\title{
Vinte anos da Rev Rene
}

\author{
Twenty years of Rev Rene
}

Como citar este artigo:

Cardoso MVLML, Pagliuca LMF. Twenty years of Rev Rene [Editorial]. Rev Rene. 2020;21:e43362. DOI: https://doi.org/10.15253/21756783.20202143362

(D)Maria Vera Lúcia Moreira Leitão Cardoso ${ }^{1}$

(D) Lorita Marlena Freitag Pagliuca ${ }^{1}$

${ }^{1}$ Universidade Federal do Ceará.

Fortaleza, CE, Brasil.

\section{Autor correspondente:}

Maria Vera Lúcia Moreira Leitão Cardoso

Rua Alexandre Baraúna, 1115 - Rodolfo Teófilo

CEP: 60430-160. Fortaleza, CE, Brasil.

E-mail: cardoso@ufc.br
Em datas significativas, é natural relembrar de fatos que marcaram a trajetória do que se está a comemorar. Discorrer sobre esses fatos, principalmente quando ilustra um caminho de muito trabalho e compromisso, enlaça-nos em sentimentos de vitória. Em júbilo e repletos de encorajamento, a Revista alcança seus vinte anos de existência.

Em 2000, foi criada com o nome de Revista da Rede de Enfermagem do Nordeste - REV. RENE, devido apresentar seu nascimento vinculado à Rede de Enfermagem do Nordeste - RENE, que objetivava promover articulação das Unidades de Ensino da área de Enfermagem da Região Nordeste, fortalecer ensino, pesquisa e extensão, e apoiar desenvolvimento de Programa de Pós-Graduação em Enfermagem para Região Nordeste. No entanto, em 2012, após idas e vindas ao caminho das políticas editoriais dos periódicos científicos, optou-se por alterar o título para Rev Rene.

Ressalta-se que os primeiros manuscritos publicados se originaram dos trabalhos apresentados em seminários desenvolvidos pelos cursos de mestrado do nordeste, os quais espelhavam o que era produzido na Enfermagem nordestina, via de regra, resultados de dissertações. Em um desses seminários, recolheram-se os trabalhos apresentados, constituiu-se um grupo que analisou um a um, selecionou-se parte deles, realizaram-se sugestões aos autores para alcançarem as condições necessárias para serem publicados. Assim, nasceu a Rev Rene! A Revista criou alma. Não éramos mais anônimos insignificantes, nem seres duplicados em imagem de televisão(1).

\section{(cc) BY}


Necessitar-se-ia de longas linhas e, provavelmente, páginas para explanar toda a história que remonta a valiosa contribuição desse periódico no crescimento científico e acadêmico da Enfermagem, no que concerne à divulgação dos conhecimentos produzidos. Inicialmente, em versão impressa (2000 - 2011). À época, tudo se fazia no papel, no correio físico, digitado, a dupla revisão não tinha a rapidez da conexão on-line de hoje. Em seguida, atingiu a versão no formato aberto, por meio eletrônico (2005), em 2012, tornou-se on-line, passando a ser periódico bimestral e bilíngue (2013), nos idiomas português e inglês, e desde 2018, adota a publicação continuada (rolling pass). Vinculada à Universidade Federal do Ceará, que abriga um Programa de Pós-graduação em Enfermagem, considerado de excelência no Brasil.

E, nesse jardim, que é regado a cada dia, em que as ervas daninhas também precisam ser retiradas! Os obstáculos também existem. Trabalha-se arduamente na busca das indexações em bases nacionais e internacionais, sendo isto porta para que pessoas do Brasil e de outros países possam também prestigiar a leitura dos artigos publicados, pondo-os à crítica, creditando citações ou não.

Desde a criação, a Rev Rene já publicou 1.567 artigos e 74 editoriais, no período de 2000 a 2019 . Tem-se debruçado a publicar temas atuais e de inte- resse da área da saúde e da Enfermagem, manuscritos de diferentes desenhos de pesquisa, advindos de todas as regiões do país e de autores estrangeiros, distanciando-se a cada ano da endogenia, embora paire a consciência de que se tem muito a fazer.

Assim, permita-se mergulhar em mares profundos e porque não, algumas vezes, devanear, para do sonho chegar ao real, ao concreto, ao vivido, ao existir desse periódico que nos faz alegrar. É resultado de várias mentes, várias mãos, isso é possível vislumbrar!

Um grupo de sonhadores que se permite sonhar, despreocupados de resultados imediatos, ciosos de construir e preservar uma história ${ }^{(1)}$, agora de 20 anos!

Congratulações para todos que demandam energias e ações de trabalho, colaboração, perseverança, otimismo na caminhada do engrandecimento da Rev Rene. Editores, revisores, pareceristas, autores, secretárias, equipe técnica... Todos os protagonistas, sejam os mais visíveis ou aqueles que, muitas vezes, no anonimato, contribuem vigorosamente para que as cenas dessa história continuem. Parabéns, Rev Rene!

\section{Referência}

1. Pagliuca LMF. 15 years of Rev Rene [Editorial]. Rev Rene. 2015; 16(1):1-2. doi: https://doi. org/10.15253/2175-6783.2015000100001 